\title{
Ferric reducing ability of plasma: a potential oxidative stress marker in stored plasma
}

\author{
Carl Hsieh, Vani Rajashekaraiah* \\ Department of Biotechnology, School of Sciences, Jain (Deemed-to-be University), Karnataka, India
}

\section{Abstract}

Introduction: The ferric reducing ability of plasma (FRAP) assay is used for measuring the antioxidant capacity. FRAP is proportional to the molar concentration of the antioxidant capacity. This study attempts to analyze the possibilities of FRAP as an indicator of oxidative stress.

Methods: Blood was drawn from male Wistar rats and stored for 20 days at $4^{\circ} \mathrm{C}$ in citrate phosphate dextrose adenine 1. The rats were divided into two groups: controls and experimentals. The experimentals were added with antioxidants - L-carnitine, curcumin, vitamin C (VC), and caffeic acid of varying concentrations - 10, 30, and $60 \mathrm{mM}(\mathrm{n}=5$ for each group). Plasma was isolated from these samples at regular intervals (every 5 days), and FRAP and protein were assayed. Results were analyzed by two-way ANOVA, using GraphPad prism 6. FRAP was maintained in controls.

Results: VC (ascorbic acid) was the most potent antioxidant in terms of FRAP during storage compared with the above antioxidants. This study emphasizes the use of FRAP as a potential marker of oxidative stress in plasma of stored blood.

Conclusion: FRAP can be utilized as a reliable marker for determining the antioxidant capacity.

Key words: plasma, antioxidants, FRAP, blood storage

Acta Haematologica Polonica 2021; 52, 1: 61-67

\section{Introduction}

Ferric reducing ability of plasma (FRAP) is an assay that is used for measuring the antioxidant power. This assay is based on the reduction of a $\mathrm{Fe}^{3+}$ complex of tripyridyltriazine $\left(\mathrm{Fe}(\mathrm{TPTZ})^{3+}\right)$ to $\mathrm{Fe}(\mathrm{TPTZ})^{2+}$ which is intensely in blue color at low pH. Excess $\mathrm{Fe}^{3+}$ is utilized and $\mathrm{Fe}(\mathrm{TPTZ})^{2+}$ is the rate-limiting factor. Thus the color formation reflects the reducing ability of the sample [1, 2]. However, FRAP was developed to give a more biologically relevant overview than individual biomarkers of oxidative stress (OS). Antioxidants (endogenous and exogenous) together provide protection against reactive oxygen species (ROS) than individual compounds. Therefore overall antioxidant capacity, such as FRAP, gives a cumulative effect of all the antioxidants present than individual components. FRAP is the only assay that measures the antioxidants directly when compared with other assays that measure the inhibition of free radicals. FRAP is directly proportional to the concentration of the electron-donating antioxidants [3]. FRAP can be used as a single test for the estimation of total antioxidant capacity of blood. FRAP describes the prooxidant-antioxidant equilibrium better than other assays [4]. FRAP does not measure thiol antioxidants and the reduction of ferric ions [5, 6]. However, FRAP has gained importance as it is simple, cost-effective, straightforward, fast, and highly reproducible compared with other tests of total antioxidant capacity [4].

During storage of blood, OS is induced which causes irreversible damage that limits its shelf life [7]. OS represents an imbalance between the ROS produced and the biological system's ability to counteract or detoxify the ROS or repair the resulting damage caused [8]. Blood and its components are stored in different storage solutions. The most commonly used storage solution is citrate phosphate dextrose adenine 1 (CPDA-1). Blood and its components possess an innate antioxidant system that helps in

\footnotetext{
*Address for correspondence: Vani Rajashekaraiah, Department of Biotechnology, School of Sciences, Block I, JAIN (Deemed-to-be University),

$\# 18 / 3,9^{\text {th }}$ Main, $3^{\text {rd }}$ Block, Jayanagar, Bengaluru 560011, Karnataka, India, phone: +91 080432 26500, +91988 617 8584, e-mail: tiwari.vani@gmail.com, vani.rs@jainuniversity.ac.in

PTHiT

Copyright (C) 2021

The Polish Society of Haematologists and Transfusiologists, Insitute of Haematology and Transfusion Medicine. All rights reserved. 
protecting itself against the ROS [9]. Since plasma holds all the blood's cellular components in suspension, it provides an overview of the OS microenvironment over storage.

Free radicals are highly unstable molecules that can cause OS, triggering cellular damage. Antioxidants combat these free radicals, thereby providing a protective effect [10]. An antioxidant is defined as "any substance that, when present at low concentrations compared to those of an oxidizable substrate, significantly delays or prevents oxidation of that substrate" [11]. Various studies have reported the beneficial effects of antioxidants (L-carnitine [LC], curcumin [Cu], vitamin C [VC]) in blood storage solutions [12-22].

LC ( $\mathrm{L}-3$ hydroxy-4-N-N-N-trimethylaminobutyrate) is one of the nutrient-derived, non-enzymatic antioxidants, which plays an important role in fatty acid turnover. LC, the biologically active stereoisomer, is an endogenous compound derived from the diet or synthesized in the liver from lysine and methionine. It acts as an antioxidant that reduces metabolic stress in cells, thus reducing OS [21, 23].

Cu (1,7-bis(4-hydroxy-3-methoxyphenyl)-1,6-heptadiene-3,5-dione) or diferuloylmethane, a component of Curcuma longa (turmeric), possesses antioxidant activity and free radical scavenging activity. $\mathrm{Cu}$ increases intracellular glutathione (GSH) and regulates antioxidant enzymes. It also protects oxyhemoglobin from nitrite-induced oxidation $[12,22]$.

$\mathrm{VC}$ or ascorbic acid is a cofactor for at least eight enzymatic reactions. Ascorbic acid acts as a reducing agent. The oxidized forms of VC are semidehydroascorbic acid and dehydroascorbic acid. Ascorbate is maintained in its reduced state by glutathione and $\mathrm{NADPH}$-dependent reactions [24, 25].

Caffeic acid (CA; 3,4-dihydroxycinnamic acid) and its conjugates (chlorogenic acid and caftaric acid) are powerful antioxidants [26]. They are ubiquitous in nature, found in almost every plant. Thus, there is a high potential to utilize this antioxidant [27]. They prevent the formation of mutagenic and carcinogenic compounds as they inhibit the $\mathrm{N}$-nitrosation reactions [28].

Studies have reported the use of FRAP to determine the antioxidant capacity of various extracts [29-33]. However, FRAP as an OS marker during blood storage has not been reported. Thus, this study attempts to analyze the possibilities of FRAP as an indicator of OS.

\section{Methods}

Animal care and maintenance was in accordance with the ethical committee regulations (841/b/04/CPCSEA).

\section{Blood sampling}

Animals were lightly anesthetized with ether and restrained in dorsal recumbancy as described earlier [34]. In brief, the syringe needle was inserted just below the xyphoid cartilage and slightly to the left of the midline. Of note, 4-5 $\mathrm{mL}$ of blood was carefully aspirated from the heart into $5 \mathrm{~mL}$ polypropylene collection tubes with CPDA-1 (sodium dihydrogen orthophosphate $2.22 \mathrm{~g} / \mathrm{L}$, citric acid $3.27 \mathrm{~g} / \mathrm{L}$, sodium citrate $26.3 \mathrm{~g} / \mathrm{L}$, dextrose $31.9 \mathrm{~g} / \mathrm{L}$, and adenine $0.27 \mathrm{~g} / \mathrm{L})[35]$.

\section{Experimental design}

Blood was drawn from 65 male Wistar rats (4 months old) and divided into two groups: controls and experimentals. The experimentals were added with antioxidants - LC, Cu, $\mathrm{VC}$, and CA of varying concentrations $-10,30$, and $60 \mathrm{mM}$ and $n=5$ for each group and stored for 20 days at $4{ }^{\circ} \mathrm{C}$. Plasma was isolated from whole blood at regular intervals (every 5 days) and assayed for FRAP (Figure 1).

\section{Plasma separation}

Plasma was isolated from $1 \mathrm{~mL}$ whole blood in microcentrifuge tubes by centrifuging in a fixed angle rotor for $20 \mathrm{~min}$ at $1,000 \mathrm{~g}$. The plasma was removed and stored at $-20^{\circ} \mathrm{C}$ for further assays [36].

\section{Ferric reducing ability of plasma}

The FRAP assay was performed as described by Benzie and Strain [2]. In brief, sample was added to freshly prepared FRAP reagent (300 mM acetate buffer [pH 3.6], $10 \mathrm{mM}$ TPTZ, and $20 \mathrm{mM} \mathrm{FeCl}_{3}$ ). The reaction mixture was incubated for $5 \mathrm{~min}$ at $37^{\circ} \mathrm{C}$ and absorbance was read at $593 \mathrm{~nm}$. FRAP was determined by using the extinction coefficient of $21,250 \mathrm{mM}^{-1} \mathrm{~cm}^{-1}$.

\section{Protein estimation}

Protein was determined in the plasma by the method of Lowry et al. [37], using bovine serum albumin (BSA) as the standard.

\section{Statistical analyses}

Results are represented as mean \pm standard error (SE). Values between the groups (storage period) and subgroups (antioxidants) were analyzed by two-way ANOVA and were considered significant at $p<0.05$. Bonferroni post-test was performed for FRAP using GraphPad Prism 6 software.

\section{Results}

Results are represented as 1) changes during the storage in all groups with day 0 and 2) changes between different concentrations against control on a particular day.

FRAP was maintained during storage in controls. Changes in FRAP were significant in all experimental groups.

\section{L-carnitine}

FRAP increased by $85 \%$ and $52 \%$ on days 10 and 20 , respectively, against day 0 in LC 10 . Decrements of $80 \%$ 


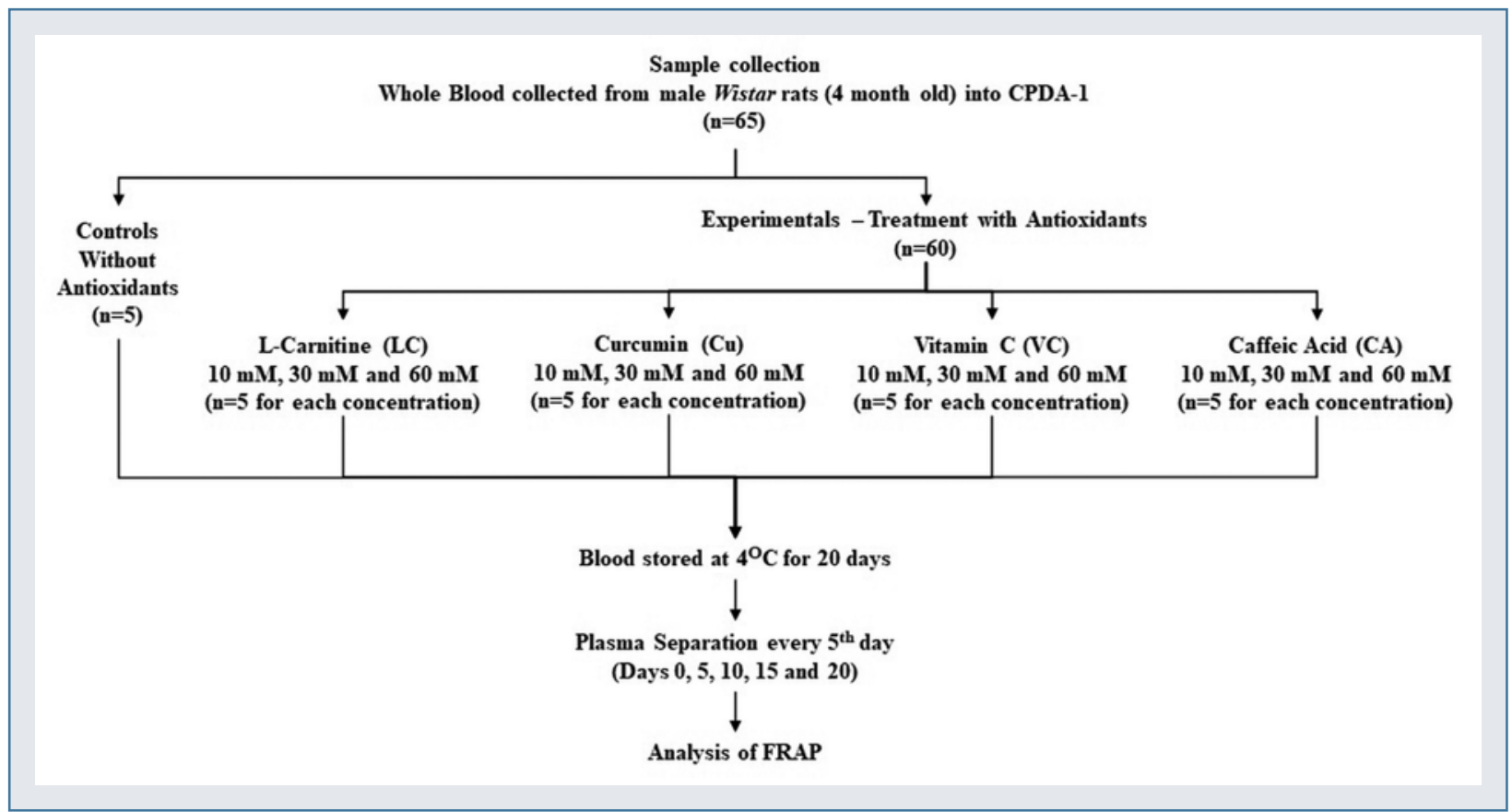

Figure 1. Experimental design; CPDA-1 - citrate phosphate dextrose adenine 1; FRAP - ferric reducing ability of plasma

were observed in LC 30 and LC 60 on all days when compared with day 0 .

Increments of $100 \%$ and $55 \%$ were observed on days 10 and 20, respectively, in LC 10 against their controls. FRAP increased by $73 \%$ on day 0 , while it decreased by $73 \%$ (days 5 and 20), and 65\% (days 10 and 15) in LC 30 and LC 60 with controls (Figure 2).

\section{Curcumin}

FRAP increased by $51 \%$ in Cu 10 on day 10 and $100 \%$ in Cu 30 from day 10 to day 20 , and Cu 60 on days $5,10,15$, and 20 against day 0 . Changes in FRAP were insignificant in $\mathrm{Cu} 10$ against controls. FRAP elevated by twofold on days 10,15 , and 20 in Cu 30 with respect to controls. Elevations of one-fold (days 5 and 15) and two-fold (days 10 and 20) were also observed in $\mathrm{Cu} 60$ (Figure 3).

\section{Vitamin C}

FRAP levels decreased by $63 \%$ (day 10), 37\% (day 15), and $55 \%$ (day 20) against day 0 in VC 10. Elevation of $42 \%$ was observed on day 5 , whereas decrements of $44 \%, 22 \%$, and $27 \%$ were observed on days 10,15 , and 20 in VC 30. FRAP elevated by 13 -fold (days 5 and 10), 16-fold (day 15), and 1-fold (day 20) in VC 60. FRAP increased by twofold on days 0 and 5 in VC 10 against their respective controls. Increments of threefold (day 0 ), fourfold (day 5), onefold (day 10), and twofold (days 15 and 20) were observed in VC 30 against controls. FRAP also elevated by threefold on days 5,10 , and 15 in VC 60 (Figure 4).

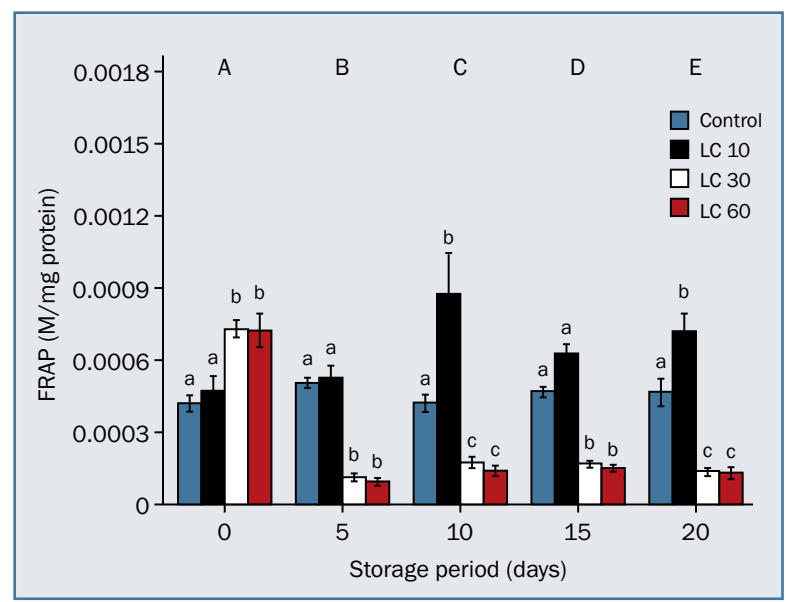

Figure 2. Effect of L-carnitine on ferric reducing ability of plasma (FRAP) during storage. $\mathrm{LC} 10=\mathrm{L}$-carnitine $10 \mathrm{mM}, \mathrm{LC} 30=\mathrm{L}$-carnitine $30 \mathrm{mM}$, and LC $60=\mathrm{L}$-carnitine $60 \mathrm{mM}$. Values are mean \pm standard error (SE) of five animals per group. Two-way ANOVA was performed between the groups and subgroups to analyze FRAP, followed by Bonferroni post-test, using GraphPad Prism 6 software. Changes between the groups (storage period) are represented in upper case. Changes within the groups (treatment-antioxidant concentrations) are represented in lower case. Those not sharing the same letters are significantly different; A, B, C, D, E - changes between the groups (storage days); $a, b, c-$ changes within the groups (treatment-antioxidant concentrations on a particular day)

\section{Caffeic acid}

FRAP was maintained in CA samples throughout the storage period. A decrement of $32 \%$ was observed in CA 10 on day 


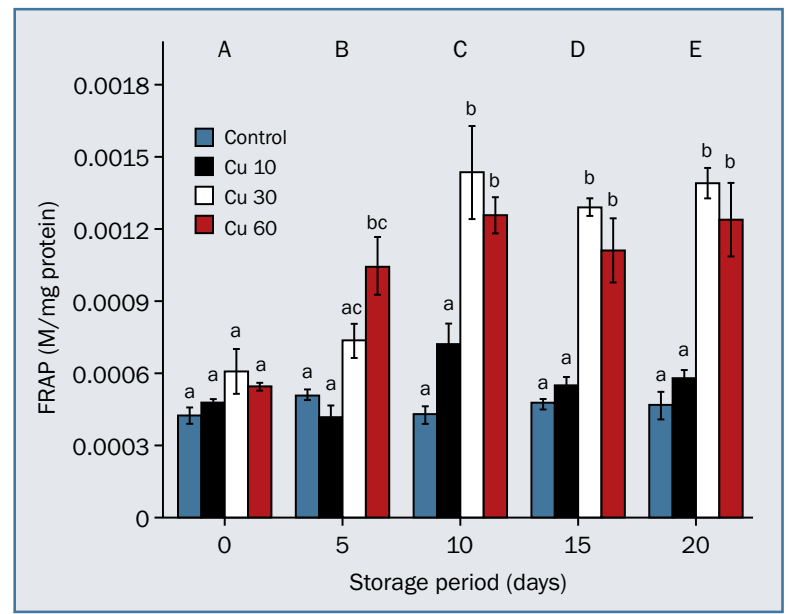

Figure 3. Effect of curcumin on ferric reducing ability of plasma (FRAP) during storage. $\mathrm{Cu} 10=$ curcumin $10 \mathrm{mM}, \mathrm{Cu} 30=$ curcumin $30 \mathrm{mM}$, and Cu 60 = curcumin $60 \mathrm{mM}$. Values are mean \pm standard error (SE) of five animals per group. Two-way ANOVA was performed between the groups and subgroups to analyze FRAP, followed by Bonferroni post-test, using GraphPad Prism 6 software. Changes between the groups (storage period) are represented in upper case. Changes within the groups (treatment-antioxidant concentrations) are represented in lower case. Those not sharing the same letters are significantly different; A, B, C, D, E- changes between the groups (storage days); $a, b, c$ - changes within the groups (treatment-antioxidant concentrations on a particular day)

20 when compared with day 0 . FRAP increased by $100 \%$ on days $0,5,10$, and 15 , and $56 \%$ on day 20 in CA 10 against controls. Increments of twofold were observed on all days in CA 30. FRAP also elevated by threefold (days 0 and 10) and twofold (days 5, 15, and 20) in CA 60 (Figure 5).

\section{Discussion}

FRAP is proportional to the molar concentration of antioxidants present. An increase in FRAP value is usually a desirable phenomenon as it proves a better protection against OS [38]. FRAP assay depends on the reduction of the TPTZ complex $\left(\mathrm{Fe}^{3+}\right.$ to $\mathrm{Fe}^{2+}$ ) by a reductant (plasma constituents) at low $\mathrm{pH}$. The $\mathrm{Fe}^{2+}$ complex results in the blue coloration that can be detected at $593 \mathrm{~nm}[8,39]$.

FRAP was maintained in controls over the storage period, indicating that the innate antioxidant system present in plasma can combat the OS induced during storage.

$\mathrm{LC}$ is an effective antioxidant as it possesses radical scavenging (superoxides, hydrogen peroxide), metal chelating activity, and great reducing power [40]. It contributes to the antioxidant defense by 1 ) directly scavenging free radicals, 2) preventing the formation of free radicals, 3) maintaining the redox state of cells, and 4) activating vitagens [41]. LC also stabilizes the energy balance across cell membranes and enhances carbohydrate metabolism,

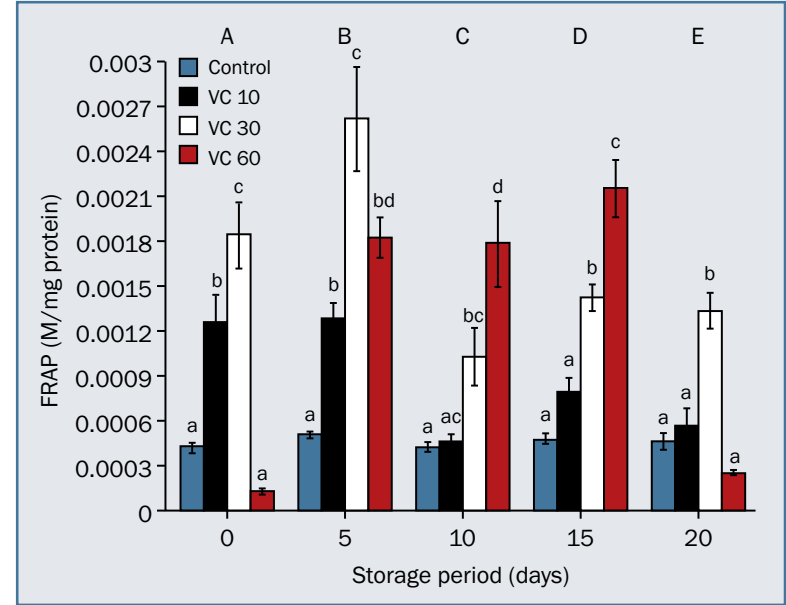

Figure 4. Effect of vitamin $C$ on ferric reducing ability of plasma (FRAP) during storage. $\mathrm{VC} 10=$ vitamin C $10 \mathrm{mM}, \mathrm{VC} 30=$ vitamin C $30 \mathrm{mM}$, and VC 60 = vitamin C $60 \mathrm{mM}$. Values are mean \pm standard error (SE) of five animals per group. Two-way ANOVA was performed between the groups and subgroups to analyze FRAP, followed by Bonferroni post-test, using GraphPad Prism 6 software. Changes between the groups (storage period) are represented in upper case. Changes within the groups (treatment-antioxidant concentrations) are represented in lower case. Those not sharing the same letters are significantly different; A, B, C, D, E - changes between the groups (storage days); $a, b, c, d$ - changes within the groups (treatment-antioxidant concentrations on a particular day)

along with maintaining the cell volume and fluid balance [42], thus protecting the erythrocyte membrane. LC reduces OS as it increases the antioxidant activity and sulfhydryls while it reduces lipid peroxidation [43]. LC at $10 \mathrm{mM}$ is more beneficial than at 30 and $60 \mathrm{mM}$ in terms of FRAP. $\mathrm{LC}$ at $10 \mathrm{mM}$ may be the optimum concentration to maintain the antioxidant capacity.

$\mathrm{Cu}$ (phenolic chain-breaking antioxidant) donates hydrogen atoms from the phenolic group or through the central methylenic hydrogen. This is responsible for the antioxidant property of $\mathrm{Cu}[44,45]$. $\mathrm{Cu}$ at higher concentrations upregulates the antioxidant enzyme activity and reduces lipid peroxidation and protein oxidation [12]. Thus FRAP was directly proportional to the concentration of $\mathrm{Cu}$.

$\mathrm{VC}$ reduces metal ions (such as iron) that are present in the active sites of mono- and dioxygenases. It acts as a co-substrate rather than a coenzyme [46]. Ascorbate also assists in the regeneration of $\alpha$-tocopherol from the $\alpha$-tocopheryl radical. It reacts with radicals to form an intermediate radical (ascorbate radical) of low reactivity. [47]. VC at all concentrations upregulated FRAP. This can be attributed to VC's potent ferric reducing ability. It reduces $\mathrm{Fe}^{3+}$ similar to hydroxylamine [48].

CA protects $\alpha$-tocopherol in low-density lipoprotein [26]. $\mathrm{CA}$ and its analogs are antioxidants with multiple mechanisms that include free radical scavenging and metal ion 


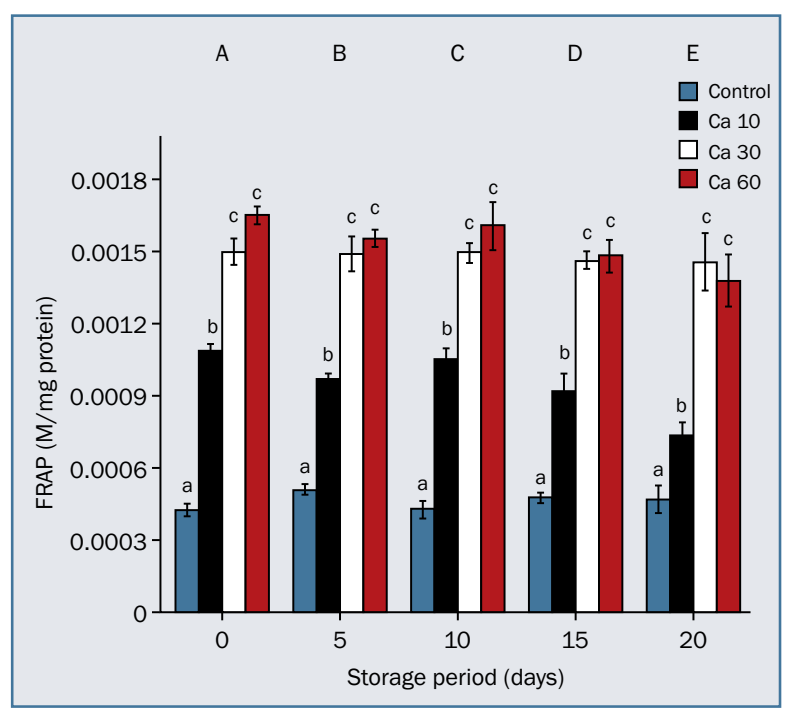

Figure 5. Effect of caffeic acid on ferric reducing ability of plasma (FRAP) during storage. $\mathrm{CA} 10=$ caffeic acid $10 \mathrm{mM}, \mathrm{CA} 30$ = caffeic acid $30 \mathrm{mM}, \mathrm{CA} 60$ = caffeic acid $60 \mathrm{mM}$. Values are mean $\pm \mathrm{SE}$ of five animals per group. Two-way ANOVA was performed between the groups and subgroups to analyze FRAP, followed by Bonferroni post-test, using GraphPad Prism 6 software. Changes between the groups (storage period) are represented in upper case. Changes within the groups (treatment-antioxidant concentrations) are represented in lower case. Those not sharing the same letters are significantly different; A, B, C, D, E - changes between the groups (storage days); $a, b, c-$ changes within the groups (treatment-antioxidant concentrations on a particular day)

chelation, and they inhibit free radical and lipid hydroperoxide formation [49]. CA increased FRAP at all concentrations and hence FRAP was proportional to the concentration of CA. This can be attributed to CA's potent free radical scavenging, metal chelating property, and its effective reducing power. It has a greater reducing power than the standard compounds such as butylated hydroxytoluene, butylated hydroxyanisole, trolox, $\alpha$-tocopherol, etc. [26].

\section{Conclusion}

FRAP is a potential marker of OS in plasma of stored blood as it reflects the antioxidant capacity and has a positive correlation with 2,2-diphenyl-1-picrylhydrazyl (DPPH) radical scavenging activity [29]. Thus, FRAP can be utilized as a reliable marker for determining the antioxidant capacity. VC (ascorbic acid) was the most potent antioxidant in terms of FRAP during storage, with respect to the above antioxidants (VC $>\mathrm{CA}>\mathrm{Cu}>\mathrm{LC})$.

\section{Acknowledgments}

The authors acknowledge Dr. Leela lyengar, Dr. Manohar SH, Dr. Soumya Ravikumar, Dr. Manasa K, and JAIN (Deemed-to-be University) for their support. The authors would also like to acknowledge the award of JAIN (Deemed-to-be University) fellowship to Mr. Carl Hsieh.

\section{Authors' contributions}

$\mathrm{CH}$ - performed the research, analyzed the data, and prepared the manuscript. VR - designed the study and edited the manuscript.

\section{Conflict of interest}

The authors have no conflict of interest (personal or financial) to disclose.

\section{Financial support \\ None.}

\section{Ethics}

The work described in this article has been carried out in accordance with The Code of Ethics of the World Medical Association (Declaration of Helsinki) for experiments involving humans; EU Directive 2010/63/EU for animal experiments; Uniform requirements for manuscripts submitted to biomedical journals.

\section{References}

1. Wojdylo A, Oszmianski J, Czemerys R. Antioxidant activity and phenolic compounds in 32 selected herbs. Food Chem. 2007; 105(3): 940-949, doi: 10.1016/j.foodchem.2007.04.038.

2. Benzie IF, Strain JJ. The ferric reducing ability of plasma (FRAP) as a measure of "antioxidant power": the FRAP assay. Anal Biochem. 1996; 239(1): 70-76, doi: 10.1006/abio.1996.0292, indexed in Pubmed: 8660627.

3. Payne AC, Mazzer A, Clarkson GJJ, et al. Antioxidant assays - consistent findings from FRAP and ORAC reveal a negative impact of organic cultivation on antioxidant potential in spinach but not watercress or rocket leaves. Food Sci Nutr. 2013; 1(6): 439-444, doi: 10.1002/ /fsn3.71, indexed in Pubmed: 24804054.

4. Hisalkar $P$, Patne A, Karnik A, et al. Ferric reducing ability of plasma with lipid peroxidation in type 2 diabetes. Int J Pharm Biol Sci. 2012; 42: 8-70.

5. Prior RL, Wu X, Schaich K. Standardized methods for the determination of antioxidant capacity and phenolics in foods and dietary supplements. J Agric Food Chem. 2005; 53(10): 4290-4302, doi: 10.1021/ /jf0502698, indexed in Pubmed: 15884874.

6. Ndhlala AR, Moyo M, Van Staden J. Natural antioxidants: fascinating or mythical biomolecules? Molecules. 2010; 15(10): 6905-6930, doi: 10.3390/molecules15106905, indexed in Pubmed: 20938402.

7. Racek J, Herynková R, Holecek V, et al. Influence of antioxidants on the quality of stored blood. Vox Sang. 1997; 72(1): 16-19, doi: 10.1046/j.1423-0410.1997.00016.x, indexed in Pubmed: 9031495.

8. Stef DS, losif G, loan-Trasca T, et al. Evaluation of 33 medicinal plant extracts for the antioxidant capacity and total phenols. J Food Agri Environ. 2010; 8: 207-10.

9. Cimen MY. Free radical metabolism in human erythrocytes. Clin Chim Acta. 2008; 390(1-2): 1-11, doi: 10.1016/j.cca.2007.12.025, indexed in Pubmed: 18243141. 
10. Desai CT. Antioxidants: fascinating and favourable biomolecules for humans. Science Innovation. 2015; 3(6): 113, doi: 10.11648/j. si.20150306.18.

11. Halliwell B, Gutteridge JM. The definition and measurement of antioxidants in biological systems. Free Radic Biol Med. 1995; 18(1): 125 -126, doi: 10.1016/0891-5849(95)91457-3, indexed in Pubmed: 7896166.

12. Carl H, Chandni A, Neha K, et al. Curcumin as a modulator of oxidative stress during storage: a study on plasma. Transfus Apher Sci. 2014; 50(2): 288-293, doi: 10.1016/j.transci.2013.12.015, indexed in Pubmed: 24462653.

13. Zan T, Tao J, Tang RC, et al. Effect of vitamin C antioxidative protection on human red blood cells. Zhongguo Shi Yan Xue Ye Xue Za Zhi. 2005; 13: $1106-8$.

14. Ibrahim IH, Sallam SM, Omar H, et al. Oxidative hemolysis of erythrocytes induced by various vitamins. Int J Biomed Sci. 2006; 2(3): 295-298, indexed in Pubmed: 23674994.

15. Shiva Shankar Reddy CS, Subramanyam MVV, Vani R, et al. In vitro models of oxidative stress in rat erythrocytes: effect of antioxidant supplements. Toxicol In Vitro. 2007; 21(8): 1355-1364, doi: 10.1016/j. tiv.2007.06.010, indexed in Pubmed: 17714909.

16. Mahmud H, Qadri SM, Föller M, et al. Inhibition of suicidal erythrocyte death by vitamin C. Nutrition. 2010; 26(6): 671-676, doi: 10.1016/j. nut.2009.11.025, indexed in Pubmed: 20338726.

17. Arduini A, Holine S, Sweeney JD, et al. Addition of L-carnitine to additive solution-suspended red cells stored at $4 \mathrm{C}$ reduces in vitro hemolysis and improves in vivo viability. Transfus. 1997; 37: 166-74.

18. Ravikumar S, Rajashekharaiah V. CUPRAC-BCS and antioxidant activity assays as reliable markers of antioxidant capacity in erythrocytes. Hematol. 2015; 20(3): 165-174, doi: 10.1179/1607845414Y.0000000177, indexed in Pubmed: 24992363.

19. Deyhim MR, Mesbah-Namin SA, Yari F, et al. L-carnitine effectively improves the metabolism and quality of platelet concentrates during storage. Ann Hematol. 2015; 94(4): 671-680, doi: 10.1007/s00277014-2243-5, indexed in Pubmed: 25399613.

20. Vani R, Soumya R, Carl H, et al. Prospects of vitamin C as an additive in plasma of stored blood. Adv Hematol. 2015; 2015: 961049, doi: 10.1155/2015/961049, indexed in Pubmed: 26345502.

21. Soumya R, Carl H, Vani R. L-carnitine as a potential additive in blood storage solutions: a study on erythrocytes. Indian J Hematol Blood Transfus. 2016; 32(3): 328-334, doi: 10.1007/s12288-015-0569-3, indexed in Pubmed: 27429526.

22. Ravikumar S, Hsieh C, Rajashekharaiah V. Prospects of curcumin as an additive in storage solutions: a study on erythrocytes. Turk J Med Sci. 2016; 46(3): 825-833, doi: 10.3906/sag-1501-93, indexed in Pubmed: 27513263.

23. Li JL, Wang QY, Luan HY, et al. Effects of L-carnitine against oxidative stress in human hepatocytes: involvement of peroxisome proliferator-activated receptor alpha. J Biomed Sci. 2012; 19: 32, doi: 10.1186/1423-0127-19-32, indexed in Pubmed: 22435679.

24. Meister A. Glutathione-ascorbic acid antioxidant system in animals. J Biol Chem. 1994; 269(13): 9397-9400, indexed in Pubmed: 8144521.

25. Michels A, Frei B. Vitamin C. In: Caudill MA, Rogers M. ed. Biochemical, physiological, and molecular aspects of human nutrition. Saunders, Philadelphia 2012: 627-654.
26. Gülçin I. Antioxidant activity of caffeic acid (3,4-dihydroxycinnamic acid). Toxicology. 2006; 217(2-3): 213-220, doi: 10.1016/j. tox.2005.09.011, indexed in Pubmed: 16243424.

27. Chen J, Но СT. Antioxidant activities of caffeic acid and its related hydroxycinnamic acid compounds. J Agric Food Chem. 1997; 45(7): 2374-2378, doi: 10.1021/jf970055t.

28. Olthof MR, Hollman PC, Katan MB. Chlorogenic acid and caffeic acid are absorbed in humans. J Nutr. 2001; 131(1): 66-71, doi: 10.1093/jn/ /131.1.66, indexed in Pubmed: 11208940.

29. Godycki-Cwirko M, Krol M, Krol B, et al. Uric acid but not apple polyphenols is responsible for the rise of plasma antioxidant activity after apple juice consumption in healthy subjects. J Am Coll Nutr. 2010; 29(4): 397-406, doi: 10.1080/07315724.2010.10719857, indexed in Pubmed: 21041815.

30. Gliszczynska-Swiglo A. Antioxidant activity of water soluble vitamins in the TEAC (trolox equivalent antioxidant capacity) and the FRAP (ferric reducing antioxidant power) assays. Food Chem. 2006; 96(1): 131-136, doi: 10.1016/j.foodchem.2005.02.018.

31. Ghasemzadeh A, Jaafar HZE, Rahmat A. Antioxidant activities, total phenolics and flavonoids content in two varieties of Malaysia young ginger (Zingiber officinale Roscoe). Molecules. 2010; 15(6): 4324-4333, doi: 10.3390/molecules15064324, indexed in Pubmed: 20657444.

32. Wang F, Zhao S, Li F, et al. Investigation of antioxidant interactions between Radix Astragali and Cimicifuga foetida and identification of synergistic antioxidant compounds. PLoS One. 2014; 9(1): e87221, doi: 10.1371/journal.pone.0087221, indexed in Pubmed: 24498048.

33. Murugan R, Parimelazhagan T. Comparative evaluation of different extraction methods for antioxidant and anti-inflammatory properties from Osbeckia parvifolia Arn. - an in vitro approach. J King Saud Univ Sci. 2014; 26(4): 267-275, doi: 10.1016/j.jksus. 2013.09.006.

34. Rajashekharaiah V, Koshy AA, Koushik AK, et al. The efficacy of erythrocytes isolated from blood stored under blood bank conditions. Transfus Apher Sci. 2012; 47(3): 359-364, doi: 10.1016/j.transci.2012.06.014, indexed in Pubmed: 22874437.

35. Vani R, Soumya R, Manasa K, et al. Storage lesions in blood components. Antioxid Med Sci. 2015; 4(3): 125, doi: 10.5455/ /oams.130915.rv.019.

36. Dodge JT, Mitchell C, Hanahan DJ. The preparation and chemical characteristics of hemoglobin-free ghosts of human erythrocytes. Arch Biochem Biophys. 1963; 100: 119-130, doi: 10.1016/00039861(63)90042-0, indexed in Pubmed: 14028302.

37. Lowry $\mathrm{OH}$, Rosenberg NJ, Farr AL, et al. Protein measurement with the Folin phenol reagent. J Biol Chem. 1951; 193(1): 265-275, indexed in Pubmed: 14907713.

38. Ognik K. Effect of L-carnitine on the level of biochemical and antioxidant indices of blood of turkey hens. Annales UMCS, Zootechnica. 2012; 30(1), doi: 10.2478/v10083-012-0004-2.

39. Prabhakar ER, Suchitra MM, Seshadri VR, et al. Ferric reducing ability of plasma and lipid peroxidation in hemodialysis patients: intradialytic changes. Nephro-Urology Monthly. 2010; 2(3): 414-421.

40. Gülçin I. Antioxidant and antiradical activities of L-carnitine. Life Sci. 2006; 78(8): 803-811, doi: 10.1016/j.lfs.2005.05.103, indexed in Pubmed: 16253281.

41. Surai PF. Antioxidant action of carnitine: molecular mechanisms and practical applications. EC Vet Sci. 2015; 2: 66-84. 
42. Flanagan JL, Simmons PA, Vehige J, et al. Role of carnitine in disease. Nutr Metab (Lond). 2010; 7: 30, doi: 10.1186/1743-7075-7-30, indexed in Pubmed: 20398344.

43. Hsieh C, Rajashekharaiah V. Influence of L-carnitine on stored rat blood: a study on plasma. Turk J Haematol. 2017; 34(4): 328-333, doi: 10.4274/tjh.2016.0343, indexed in Pubmed: 28044994.

44. Barclay LR, Vinqvist MR, Mukai K, et al. On the antioxidant mechanism of curcumin: classical methods are needed to determine antioxidant mechanism and activity. Org Lett. 2000; 2(18): 2841-2843, doi: 10.1021/ol000173t, indexed in Pubmed: 10964379.

45. Menon VP, Sudheer AR. Antioxidant and anti-inflammatory properties of curcumin. Adv Exp Med Biol. 2007; 595: 105-125, doi: 10.1007/978-0-387-46401-5_3, indexed in Pubmed: 17569207.

46. Barrita JL, Sánchez MD. Antioxidant role of ascorbic acid and his protective effects on chronic diseases and his protective effects on chronic degenerative diseases. Intech, Rejeka 2013: 449-484. https://www.intechopen.com/books/oxidative-stress-and-chronic-degenerative-diseases-a-role-for-antioxidants/antioxidant-role-of-ascorbic-acid-and-his-protective-effects-on-chronic-diseases (May 13, 2021).

47. Halliwell B. Vitamin C: antioxidant or pro-oxidant in vivo? Free Rad Res. 1996; 25: 439-454.

48. Elmagirbi A, Sulistyarti $\mathrm{H}$, Atikah A, et al. Study of ascorbic acid as iron(III) reducing agent for spectrophotometric iron speciation. J Pure Appl Chem Res. 2012; 1(1): 11-17, doi: 10.21776/ /ub.jpacr.2012.001.01.101.

49. Son S, Lewis BA. Free radical scavenging and antioxidative activity of caffeic acid amide and ester analogues: structure-activity relationship. J Agric Food Chem. 2002; 50(3): 468-472, doi: 10.1021/jf010830b, indexed in Pubmed: 11804514. 